\title{
Managing organizational change: Decision's maker perceptions in the UAE manufacturing industry
}

\author{
Yazeen, Zahi $\bowtie$ \\ College of Business Studies, Al Ghurair University, Dubai, UAE (eibfs@yahoo.com) \\ Okour, Adnan \\ College of Business Studies, Al Ghurair University, Dubai, UAE (adnan@agu.ae)
}

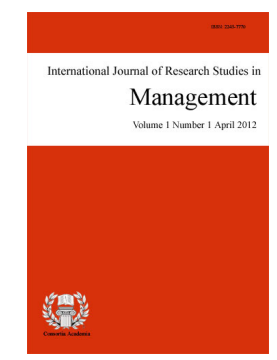

ISSN: 2243-7770 Online ISSN: 2243-7789

OPEN ACCESS

\begin{abstract}
This paper aims to examine the common practices of change projects in the manufacturing industry in UAE and the key factors for effective implementation and highlighting the roadblocks of organizational change. The primary data were collected through pre-interview questionnaires and analyzed using Multivariate Analysis of Variance (MANOVA). The findings revealed that technology change is the change most practiced by the UAE manufacturing industry, then strategy development, TQM driven change, and software development with less emphases on cultural change. The usable data were restively small $(n=150)$. Further research could be done with a larger sample to test the findings. The paper offers rare insight into change management practices in the manufacturing industry in UAE in addition to the initiators' perception of key factors of effectiveness or the roadblocks of organizational.
\end{abstract}

Keywords: change management; change leadership; organization development; UAE manufacturing sector; change agent 


\section{Managing organizational change: Decision's maker perceptions in the UAE manufacturing industry}

\section{Introduction}

During the last two decades, the manufacturing sector has made significant progress in the UAE, due to the government's emphasis on reducing its economic dependency on oil. Manufacturing in the UAE today covers a wide range of activities such as cement, aluminum, garments, plastics, fiberglass, and foodstuffs. But the UAE is open to global competition, including neighboring Gulf countries and China, who produce similar products with a very competitive price. Due to constraints in domestic market size, limited supply of labor, and globalization, the UAE manufacturing sector needs to be well restructured with advanced technologies, improve competency, and efficiency of operation through proactive organizational change management.

Moran and Avergun's (1997) definition of change management provides a starting point, defining it as the process of continually renewing the organization's direction, structure, and capabilities to serve the ever-changing needs of the marketplace, the organization, and employees. Change management plays an important role in any organization and one of the important disciplines of technology infrastructure management (Moran \& Brightman, 2000). A 2002 article that integrated the results of 49 studies on major change projects found that complex initiatives fail $67-81 \%$ of the time (Smith, 2002). The 49 major change projects are strategy development (3), restructuring and downsizing (9), technology change (5), mixed change efforts (1), TQM driven change (5), mergers and acquisitions (9), reengineering and process design (7), software development and installation (6), business expansion (1), and cultural change (3).

Change management takes courage precisely because it can be a high-risk undertaking both for organizations and the careers of the decision-makers involved. In consequence, many initiatives nominally supposed to manage change are either ineffective in their original formulation or rendered so by the process of implementation - often as a result of internal resistance to new initiatives. Studies indicate that some 50-70\% of change management initiatives fail to make any lasting impact on the organization they purport to reform (LaClair \& Rao, 2002). Most significant change fails to meet the expectations and targets of the decision-makers involved. The failure is blamed on resistance. Decision makers are frequently unreasonable in their expectations and time scale, forgetting the process they went through when they decided to make the change. Whether there are other factors that contribute to the success or failure of organizational change efforts, this study seeks to explore the common practice of change and the possible common key factors that contribute to making the change smoother.

\subsection{Significance of the study}

There is a general awareness of the intense challenges faced by organizations, specifically in the Gulf region. In view of a threatening and turbulent business environment, the need for organizations to make continuous strategic responses towards this ever-increasing changing market is crucial to sustain success and to learn more about what creates successful change (Kotter, 1996). However, from the lecturer review, about $70 \%$ of organizational transformations fail. Rarely is the cause a flawed strategy or lack of commitment by leaders. Usually, said de Lima (2009), failure occurs because the organization never wins its employees' commitment. Most experts are obsessed with "soft" issues, such as culture and motivation, but focusing on these issues alone won't bring about change.

Companies also need to consider the hard factors--like the time it takes to complete a change initiative, the number of people required to execute it (Sirkin, Keenan, \& Jackson, 2005). Resistance to change does not necessarily reflect opposition, nor is it merely a result of inertia. Instead, even as they hold a sincere commitment 
Managing organizational change: Decision's maker perception in the UAE manufacturing industry

to change, many people unwittingly apply productive energy toward a hidden competing commitment. The resulting internal conflict stalls the effort in what looks like resistance but is, in fact, a kind of personal immunity to change (Kegan \& Lahey, 2001). To improve the UAE manufacturing capabilities in managing change programs' effectiveness, it's crucial to explore and learn about these practices of designing such programs that are vital to the success of any field of change management.

\subsection{Research objectives}

In order to enhance the effectiveness of future change management program efforts, decision makers have to learn the current practices of such programs that differentiate successful ones from the unsuccessful. This helps enhance their understanding about the key factors that contribute to the relative success or failure of the change management programs in a UAE context. Specifically, this study was directed to provide insights into the following objectives:

1. What are the common activities of change management in the UAE?

2. What are the managers' degrees of success vs. failure of managing change?

3. What are the factors that contribute in change management successfulness?

4. What are the roadblocks of organizational change?

5. What is the significance of research findings?

\section{Research background}

Mohammed bin Rashid Al-Maktoum, Crown Prince and UAE Defense Minister, has told government departments to break free of old structures and meet the challenges of a globalize world, and in turn, the government would prepare future leaders by encouraging them to raise standards.

We won't allow anyone to undermine the development of our valuable human resources. It's not enough to provide the best education, health and social care for our citizens and then throw them to work in jobs controlled by rigid and outdated management (structures) that oppose growth and development, (Arab News, 2004)

The UAE had begun opening up to free trade, encouraging the relatively free movement of labor, and forming joint business ventures long before it became a necessity as part of the globalization trend that has been sweeping the world following the collapse of the Soviet Union in 1991 (APS Diplomat Fate of the Arabian Peninsula, 2002). The balance of power in the Gulf Cooperation Council (GCC members are Bahrain, Oman, Kuwait, Saudi Arabia, Qatar and United Arab Emirates) manufacturing sector is dominated by Saudi Arabia, with investments exceeding \$150 billion until 2008 and the number of plants set up exceeding 4,437 with a total workforce of more than 472,000 (Gulf News, 2009). The competition also is coming from other neighboring countries like Qatar, Kuwait, Iran, and from other Far East countries like China and South Korea. According to Arab News (2009), The competition has boiled down to 10 countries being deemed good enough, with Japan, Saudi Arabia, UAE, Iran, China and South Korea all having four teams in contention.

\section{Methodology}

This section reports the research methodology, including population, sampling, measuring instruments, and data collection and statistical data analysis. Descriptive data analysis and frequency were also used in this research 


\subsection{Participants}

The research study was an interview questionnaire survey that focused on organizations in UAE. The population frame was drawn from 1,000 organizations listed in the directory of the Etisalat Yellow Pages. A random sampling was used to select 350 sample survey questionnaires. The sample size was based on the generalized scientific guideline for sample size decisions (Sekaran, 2000). The respondents for this study comprised $150 \mathrm{CEOs/managers,} \mathrm{or} \mathrm{those} \mathrm{who} \mathrm{responsible} \mathrm{for} \mathrm{managing} \mathrm{change} \mathrm{programs} \mathrm{from} \mathrm{a} \mathrm{cross-section} \mathrm{of}$ organizations.

\subsection{Data collection}

Field data collection was accomplished by interview questionnaire survey between March and September 2009 in UAE. The questionnaire with a cover letter describing the purpose of the study was presented to the $\mathrm{CEO} /$ managing director of each sample organization, with a request that it be answered by the chief executive officer, director, coordinator, manager or the person responsible for change management programs. For non-response samples, an enquiry was made and the major reasons cited were lack of interest, confidentiality, the in-charge person was out of the office, or corporate policy was to not disclose information. Despite the comparatively low respondent rate, which is typical for interview surveys, the number of responses is sufficient for the purpose of this exploratory study.

\subsection{Questionnaire development}

1. Role of change

2. Type of manufacturer

3. Level of education

4. Years of experience

5. Initiator of change

6. Types of change

7. Latest completed change projects

8. Positive factors influence change

9. Negative factors influence change

\section{Findings}

A total of 150 responses were received from this study. Table 1 provides descriptive statistics of the respondents. Forty-five percent of the respondents were senior management executives, who hold titles like "CEO" or "Owner," while 19\% were from executives or managers, $24 \%$ from professionals or technical, and $12 \%$ from others such as assistant managers, coordinators, and supervisors. The respondents come from a wide range of manufacturing industries from different sizes in UAE as described in the second part of Table 1. The third part of Table 1 determines the role of managing change programs by participants. The majority of participants lack the role in managing change programs in their manufacturing and only $48 \%$ have a $100 \%$ role in managing change in their manufacturing company.

Participants were asked about their level of education, major, and years of experience. The results in Table 2 indicated that $13 \%$ held master's degrees, $57 \%$ held bachelor's degrees, and $27 \%$ held other college degrees, while $3 \%$ had no educational degree. But when the participants asked about the relationship between their levels 
Managing organizational change: Decision's maker perception in the UAE manufacturing industry

of education to management discipline, only $65 \%$ of them had majors in management and the other $35 \%$ held different educational degrees in computers, engineering, graphic design, and the humanities. Managerial skills play a crucial role in change management success. Participants were also asked about their years of experience, and Table 2 shows the data that was drawn from the respondents.

\section{Table 1}

Illustrates the role of change, type of manufacturer, and role in managing change $(N=150)$

\begin{tabular}{llcc}
\hline & Items & $n$ & $\%$ \\
\hline Position & CEO/Owner & 68 & 45 \\
& Executive/ Manager & 28 & 19 \\
& Professional/Technical & 36 & 24 \\
& Others & 18 & 12 \\
& & & 61 \\
Types of manufacturer & Heavy & 92 & 24 \\
& Light & 36 & 15 \\
Role in managing change & High-tech & 22 & 48 \\
& & & 40 \\
& & 73 & 90 \\
\end{tabular}

Table 2

Illustrates the level of education and years of experience $(N=150)$

\begin{tabular}{llrr}
\hline & Items & $n$ & $\%$ \\
\hline Level of education & Ph.D. & 0 & 0 \\
& Master & 20 & 13 \\
& Bachelor & 85 & 57 \\
& College & 41 & 27 \\
& None & 4 & 3 \\
& & & 65 \\
If degree is related to management & Yes & 97 & 35 \\
& No & 53 & 5 \\
Years of experience & & & 35 \\
& $<3$ years & 5 & 29 \\
& From 3-5 & 53 & 31 \\
\hline
\end{tabular}

The participants were asked who the change initiators. Figure 1 summarizes the results, Fifty percent indicated that the CEO or the president of the company was who initiated change programs, while $46 \%$ indicated that the managers were who initiated change programs in their companies. It's surprising that the vice presidents of the respondents almost had no role in initiating change programs. Four percent indicated that others are change initiators, such as professionals, technical positions, and supervisors. 


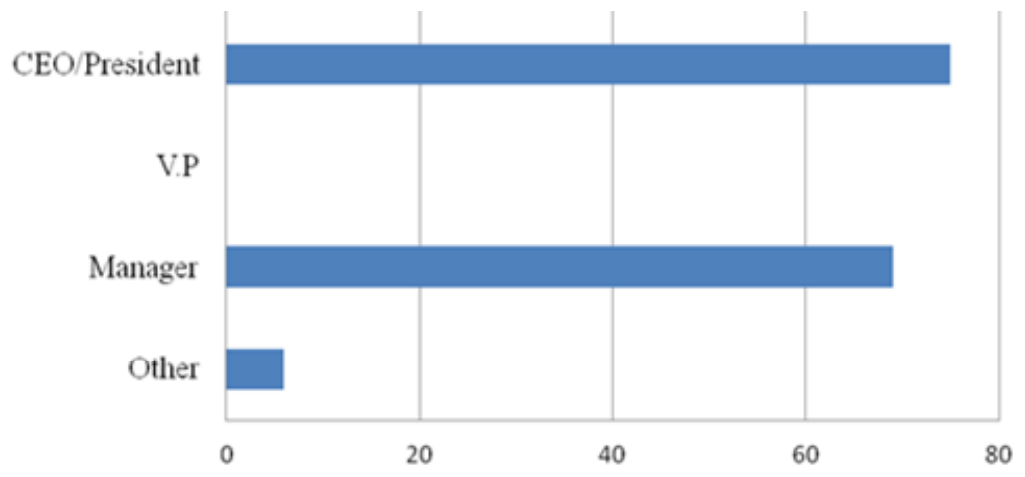

Figure 1. Initiators of change

Respondents were asked about the most recent change programs implemented in their companies, and figure 2 summarizes the results. 36 percent indicated that the technology change programs are the most recent change programs implemented in their companies. Technology change means installing a new system to influence the whole company. Only 16 percent indicated that total quality management change programs were implemented recently in their organizations. TQM also includes ISO 2000 and ISO 14000. 16 manufacturers out of 150 experienced recently reengineering and process design programs. 20 percent indicated that their organizations recently implemented strategy development programs. Only ten percent indicated that they implemented software development and installation recently. It's surprising that only two percent indicated that cultural change was implemented recently in their organizations. Three percent of total respondents indicated that other change programs recently were implemented in their manufacturing companies, such as outsourcing, cutting costs, and relocation.

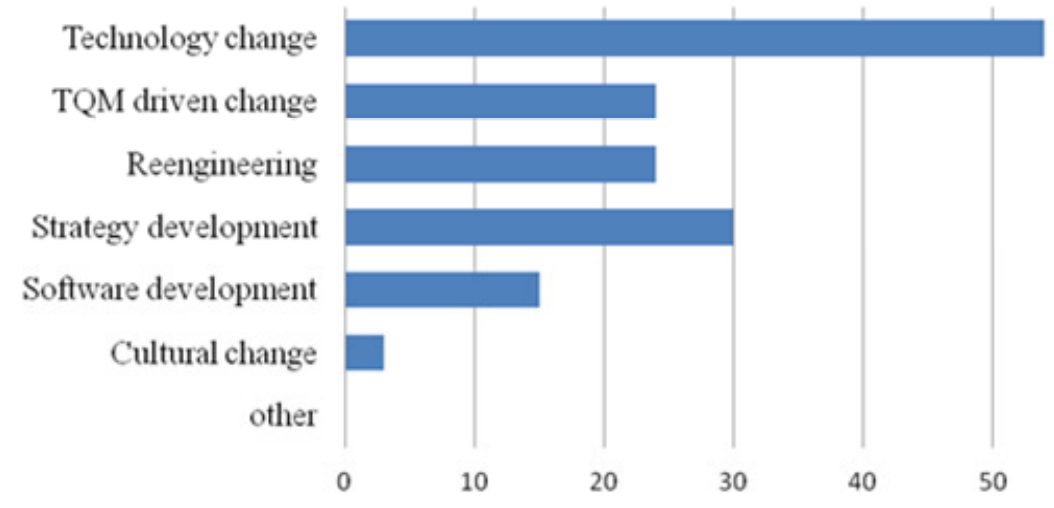

Figure 2. Types of change

Respondents were asked to rate the level of success or failure in the change programs recently implemented in their companies, and figure 3 summarizes the results. 17 percent of the respondents indicated that their recent change programs were successfully implemented, but 51 percent of the respondents indicating they just passed. The objectives of the change programs were fully achieved and the results were delightful in the opinion of the first group, while the second group explained passed as the objectives of the change programs were met as expected. 14 and 15 percent of the respondent indicated that their recent change programs were left no change or failed, respectively. Only 3 percent of the participants explained the results of their recent change programs as not measured because no objectives were set for the new programs or they did not evaluate the effectiveness of the change programs. 


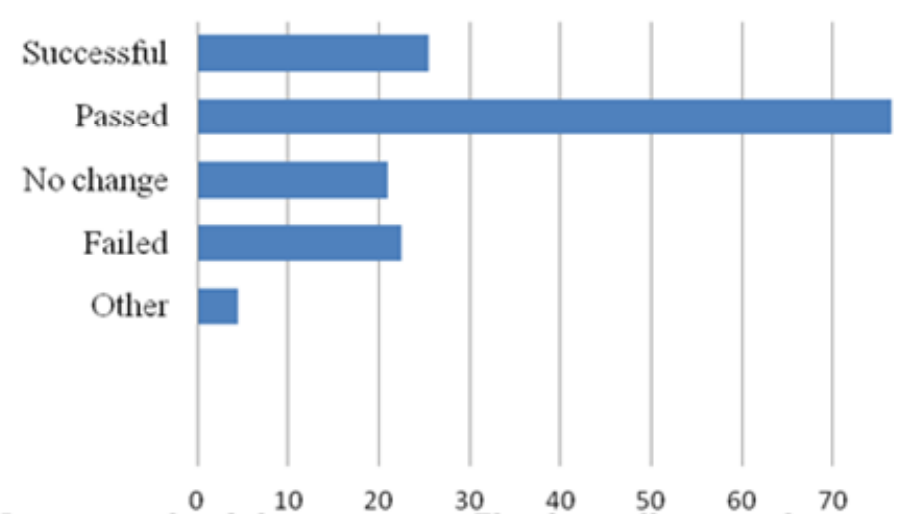

Figure 3. Latest completed change projects

The participants were asked about the key factors that influence change programs success, and these details appear in Table 3. Ninety-three percent agreed that the role of leadership commitment and support were key factors in change management success. Sixty percent agreed that clear and measurable objectives are crucial in change management success. Sixty-five percent also agreed that a well-designed execution plan is also crucial in change management success. Only forty-seven percent agreed that the employees' involvement and commitment was crucial in change management succession, while forty-five percent disagreed on the importance of employees' involvement and commitment in change management. Finally, seventy-one percent agreed about the importance of methods to evaluate, measure, and track results in change management.

Table 3

Key factors that influence change project success $(N=150)$

\begin{tabular}{|c|c|c|c|c|c|}
\hline Items & $\begin{array}{l}\text { Strongly } \\
\text { agree }\end{array}$ & Agree & Neutral & Disagree & $\begin{array}{l}\text { Strongly } \\
\text { disagree }\end{array}$ \\
\hline $\begin{array}{l}\text { Leadership commitment and } \\
\text { support }\end{array}$ & 79 & 14 & 4 & 2 & 1 \\
\hline $\begin{array}{l}\text { Clear and measurable } \\
\text { objectives }\end{array}$ & 43 & 27 & 11 & 19 & 0 \\
\hline $\begin{array}{l}\text { Clearly defined roles and } \\
\text { responsibilities }\end{array}$ & 65 & 23 & 3 & 8 & 1 \\
\hline Well-designed execution plan & 23 & 42 & 10 & 18 & 1 \\
\hline $\begin{array}{l}\text { Employees' involvement and } \\
\text { commitment }\end{array}$ & 31 & 16 & 8 & 44 & 1 \\
\hline $\begin{array}{l}\text { Methods to evaluate, } \\
\text { measure, and track results }\end{array}$ & 17 & 54 & 12 & 11 & 6 \\
\hline
\end{tabular}

Note. Values are in percentage.

Table 4 describes the reasons for change management failure in the eyes of the 150 participants in this research paper. Ninety percent agreed that the lack of leadership support could cause change management failure. Only 50\% agreed that the culture could be a reason for change management failure. Only $51 \%$ agreed that the lack of employee support and commitment could be a reason for change management failure. Finally, only $42 \%$ believed that the unclear change program's objectives could be a reason for change management failure.

By examining the relationship between degree of education that is related to the management field and the success or failure in recent change management programs implemented, Table 5 and 6 along with figure 4 shows the relationship between the two variables examined using a Pearson Correlation. The results suggest a weak 
Yaseen, Z. \& Okour, A.

positive relationship $(+0.466)$ between the level of success or failure of recently implemented change programs and the correlation with the decision maker's educational degree and whether it was related to the management field.

Table 4

Reasons for change management failure $(N=150)$

\begin{tabular}{|c|c|c|c|c|c|}
\hline Items & $\begin{array}{l}\text { Strongly } \\
\text { agree }\end{array}$ & Agree & Neutral & Disagree & $\begin{array}{l}\text { Strongly } \\
\text { disagree }\end{array}$ \\
\hline Lack of leadership support & 81 & 9 & 7 & 1 & 2 \\
\hline $\begin{array}{l}\text { Culture does not support the } \\
\text { change }\end{array}$ & 18 & 32 & 13 & 28 & 9 \\
\hline $\begin{array}{l}\text { Lack of employees support } \\
\text { and commitment }\end{array}$ & 12 & 39 & 8 & 31 & 10 \\
\hline Unclear objectives & 23 & 19 & 6 & 44 & 8 \\
\hline Other reasons & & & & & \\
\hline
\end{tabular}

Note. Values are in percentage.

\section{Table 5}

The relationship between the degree of education and the level of success or failure $(N=150)$

\begin{tabular}{lcc}
\hline \multicolumn{1}{c}{ Factors } & If Degree is related to management & Level of success or failure \\
\hline If Degree is related to management & 1 & \\
Level of success or failure & $0.466(* *)$ & 1 \\
\hline
\end{tabular}

Note. ${ }^{* *} p<0.01$

Table 6

The relationship between the degree of education and the level of success or failure $(N=150)$

\begin{tabular}{lccccc}
\hline \multicolumn{1}{c}{ Items } & $\mathrm{N}$ & Minimum & Maximum & Mean & $S D$ \\
\hline If Degree is related to management & 150 & 1 & 2 & 1.35 & 0.48 \\
Level of success or failure & 150 & 1 & 5 & 2.36 & 1.02 \\
Valid N (listwise) & 150 & & & & \\
\hline
\end{tabular}

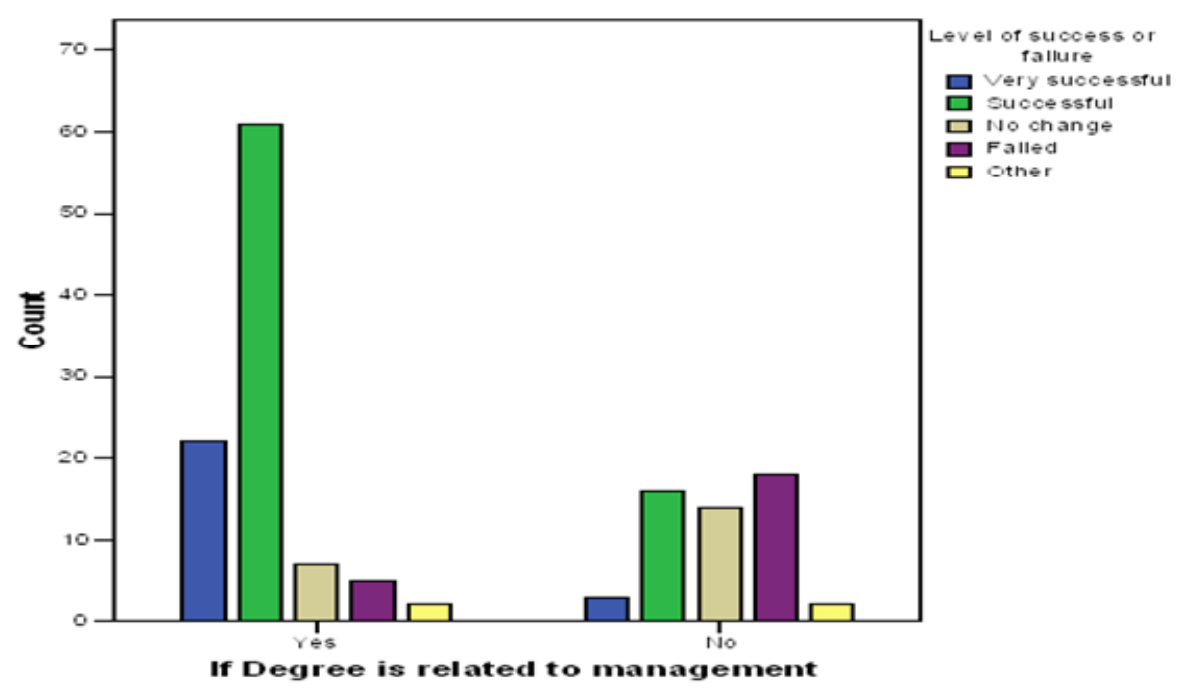

Figure 4. Shows relationship between the degree of education and the level of success or failure 
Managing organizational change: Decision's maker perception in the UAE manufacturing industry

By examining the relationship between years of experience and the rate of succession or failure in recent implementation change management programs, the results in Table 7 and 8 along with figure 5, show a weak positive relationship $(+0.244)$ between the two variables.

Table 7

The relationship between years of experience and the level of success or failure $(N=150)$

\begin{tabular}{lcc}
\hline \multicolumn{1}{c}{ Factors } & Years of experience & Level of success or failure \\
\hline Years of experience & 1 & \\
Level of success or failure & $0.244(* *)$ & 1 \\
\hline
\end{tabular}

Note. ${ }^{*} p<0.01$

\section{Table 8}

The relationship between years of experience and the level of success or failure $(N=150)$

\begin{tabular}{lccccc}
\hline \multicolumn{1}{c}{ Items } & $\mathrm{N}$ & Minimum & Maximum & Mean & $S D$ \\
\hline Years of experience & 150 & 1 & 4 & 2.85 & 0.93 \\
Level of success or failure & 150 & 1 & 5 & 2.36 & 1.02 \\
Valid N (listwise) & 150 & & & & \\
\hline
\end{tabular}

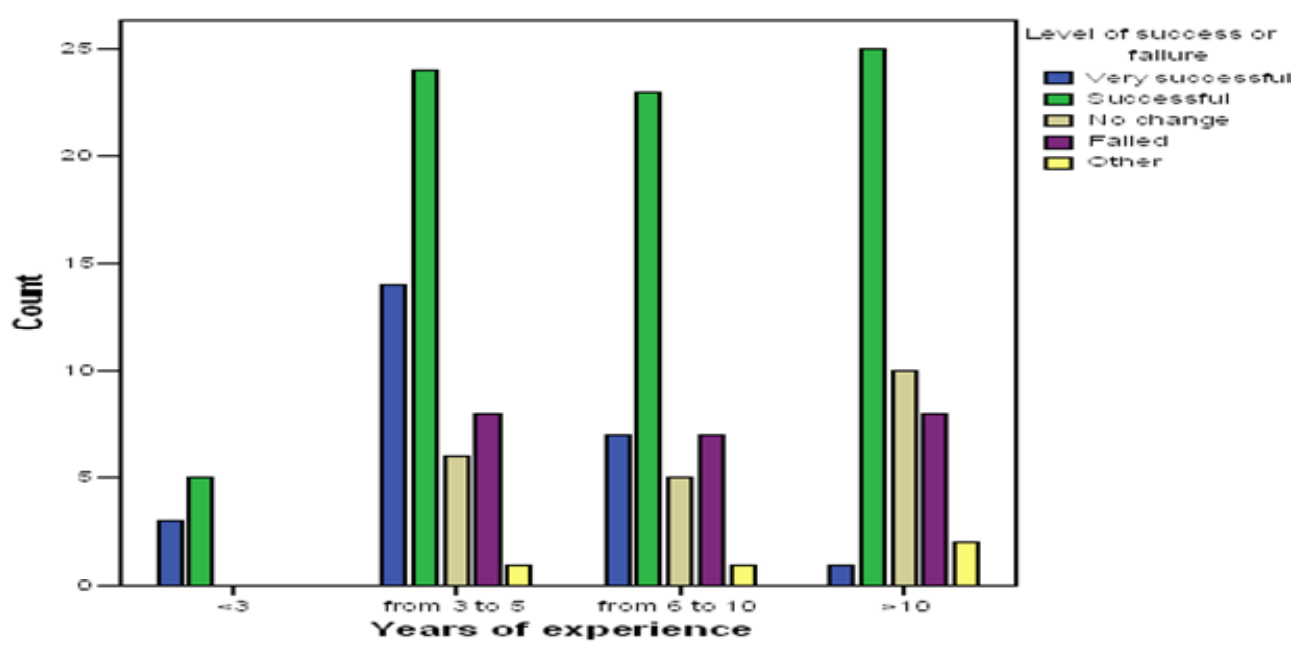

Figure 5. Shows the relationship between years of experience and the level of success or failure

\section{Conclusions and discussions}

The goal of this study was to examine the common practices of change projects in the manufacturing industry in the UAE and the key factors for effective implementation and highlighting the roadblocks of organizational change. As mentioned in the literature review, the high failure rates of change-management initiatives indicate the difficulty and complexity of the change process. In a study of 40 major change management programs, it was found that $58 \%$ failed and $20 \%$ captured only a third or less of the value expected (LaClair \& Rao, 2002).

The research findings suggest that technology change and strategy development (37\% and 21\%, respectively) are the change management programs most implemented recently in the manufacturing industry. The research results also suggest that the percentage of implementation results of change either successful or passing are $17 \%$ and $51 \%$, respectively, while the percentage of no change and or no failure after implementing such changes are $14 \%$ and $15 \%$, respectively. The results indicated a weak positive relationship between years of experience or 
the degree of education, whether it was related to management, and the rate of succession or failure in the recently implemented change programs.

The research findings highlight the key factors that support the change programs to transform the organization successfully, as well as the key factors that disrupt the transformation.

D Leadership commitment and support: 79\% strongly agreed and 14\% agreed on the importance of the role of the leader through change. Kanter (2003) emphasized leadership skills in conceiving and managing change projects, whether they are innovations in established organizations, culture, and process changes, or entrepreneurial ventures for industry or social change. The skills that leaders need are different at various phases of change projects.

$>$ Clear and measurable objectives: $43 \%$ strongly agreed, $27 \%$ agreed, $11 \%$ were neutral, and $19 \%$ disagreed on the role of clear and measurable objectives in smoothing the process of change projects. It's important to articulate smart objectives to measure the degree of achievement. Setting objectives is a key step in strategic project planning and assessment (Goold \& Campbell, 2002).

$>$ Clearly defined roles and responsibilities: 65\% strongly agreed and 23\% agreed. When employees don't know their roles and responsibilities, workplace chaos can result.

$>$ Well-designed execution plan: $23 \%$ strongly agreed, $42 \%$ agreed, and $27 \%$ disagreed on the importance of a well-designed execution plan of change management. An execution plan is also a key to strategic success, but few managers know how to plan and they don't know how to apply it in real life, causing many problems for their organizations. Strategy execution is difficult but worthy of management's attention across all levels of an organization. All managers bear responsibility for successful execution. It is not just a lower-level task.

$>$ Employees' involvement and commitment: 31\% strongly agreed and 16\% agreed, while $44 \%$ disagreed on the importance of employees' involvement in change management. Faced with the need for a massive change, most managers respond predictably, according to David and Michael (2005), and they revamp the organization's strategy, shift around staff, and root out inefficiencies. They then wait patiently for performance to improve, only to be bitterly disappointed because they've failed to prepare employees adequately for the change. Motivating employees and providing effective communications are each highly and significantly associated with effective implementation of change (Hebda, Vojak, Griffin, \& Price, 2007).

Methods to evaluate, measure, and track results: $17 \%$ strongly agreed, 54\% agreed, and 29\% disagreed, strongly disagreed or were neutral on the importance of implementing methods to evaluate, measure, and track results of change programs. Observable variables such as production, revenue, profit, and customer satisfaction may have allowed for additional bottom-line conclusions. The balanced scorecard seems to be the most influential and dominant concept of evaluation results (Neely, 2002).

$>$ Culture does not support the change: $18 \%$ strongly agreed, $18 \%$ agreed, $13 \%$ were neutral, $28 \%$ disagreed, and $9 \%$ strongly disagreed. Culture change is an important part of the change management process. The way employees work, their attitudes toward work and change, their relationships with each other and management - it all has an impact on how well or poorly change is adopted and sustained. A roadblock to successful implementation of structural change programs, such as a TQM or re-engineering, is the vulnerability of such initiatives to powerful, yet poorly understood, cultural influences (Heilpern \& Nadler, 1992).

\subsection{Limitation of the study}

Judging from the relatively small sample size and the ratings of success in change programs by respondents, 
Managing organizational change: Decision's maker perception in the UAE manufacturing industry

the study requires the use of simple statistical analysis techniques. Related findings should be considered tentative and should be further confirmed by future research with a larger sample size. Descriptive data analysis and frequency were used to explore common change programs practices in UAE organizations.

\subsection{Recommendation}

HR is playing a prominent role in the reorganizing and restructuring of organizations worldwide; thus, HR in the UAE manufacturing industry should become a strategic partner with the business. HR people must have the capabilities to recruit the right candidates in the right positions and help managers build leaders and careers. Manufacturers in UAE must revise their perceptions of HR in order to be viewed as a strategic partner.

$>\quad$ Culture has a powerful effect on the performance and long-term effectiveness of organizations, as well as employee morale, commitment, productivity, physical health, and emotional well-being. Decision makers in UAE manufacturers should be aware of culture change processes before implementing a change program to help them succeed.

$>\quad$ Leaders play a core role in change succession in preparing for change, through change, and after implementation of the change program. Leaders should create a trust environment through the time of change, because employees will look towards the leaders for effective planning, effective decision making, and complete communication because employees perceive leadership as supportive, concerned, and committed to their welfare.

$>\quad$ The restructuring process should be considered an ongoing one in the manufacturing industry in UAE to compete internationally. The shifts for liberalization and privatization to the region toward open markets force UAE manufacturers to compete globally.

\section{References:}

APS Diplomat Fate of the Arabian Peninsula. (2002). THE UAE - The challenge of globalization - Part 19. Retrieved November 10, 2011, from http://www.thefreelibrary.com/THE+UAE+-+The+Challenge+Of+Globalisation+-+Part+19.-a0893721 $\underline{77}$

Arab News. (2004). UAE minister tells officials to face globalization challenges. Retrieved November 10, 2011, from $\mathrm{http}: / / \mathrm{www}$.arabnews.com/?page $=4 \&$ section $=0 \&$ article $=43527 \& \mathrm{~d}=21 \& \mathrm{~m}=4 \& \mathrm{y}=2004$

Arab News. (2009). Saudi outfits ready to face Asian professional league rivals. Retrieved November 10, 2011, from $\mathrm{http}: / /$ archive. arabnews.com/?page $=8 \&$ section $=0 \&$ article $=120116 \& \mathrm{~d}=10 \& \mathrm{~m}=3 \& \mathrm{y}=2009$

de Lima, J. A. (2009). Managing change: Winning hearts and minds, balanced scorecard report. Harvard Business Review, 11(1), 16.

Goold, M., \& Campbell, A. (2002). Designing effective organizations: How to create structured networks. San Francisco, CA: Jossey-Bass.

Gulf News. (2009). Manufacturing Saudi Arabia leads in manufacturing sector investments. Retrieved November 10, 2011, from http://www.gulfnews.com/business/Industry/10293038.html

Hebda, J. M., Vojak, B. A., Griffin, A., \& Price, R. L. (2007). Motivating technical visionaries in large American companies. IEEE Transactions on Engineering Management, 54(3), 433-444. doi: 10.1109/TEM.2007.900791 <http://dx.doi.org/10.1109/TEM.2007.900791>

Heilpern, J. D., \& Nadler, D. A. (1992). Implementing Total Quality Management: A process of cultural change. In D. A. Nadler, M. S. Gerstein \& R. B. Shaw (Eds.), Organizational architecture. Designs for changing organizations. San Francisco, CA: Jossey-Bass.

Kanter, R. M. (2003). Leadership for change: Enduring skills for change masters. Boston, MA: Harvard Business Review.

Kegan, R., \& Lahey, L. L. (2001). Real reasons people won't change. Harvard Business Review, 79(10), 145-154.

Kotter, J. P. (1996). Leading change. Boston, MA: Harvard Business School Press.

LaClair, J., \& Rao, R. (2002). Helping employees embrace change. The McKinsey Quarterly(4).

Moran, J. W., \& Avergun, A. (1997). Creating lasting change. The TQM Magazine, 9(2), 146-151. doi: 
Yaseen, Z. \& Okour, A.

10.1108/09544789710165590<http://dx.doi.org/10.1108/09544789710165590>

Moran, J. W., \& Brightman, B. K. (2000). Leading organizational change. Journal of Workplace Learning, 12(2), 66-74. doi: 10.1108/13665620010316226 <http://dx.doi.org/10.1108/13665620010316226>

Neely, A. (2002). Business performance measurement. London, UK: Economist Books. $<$ http://dx.doi.org/10.1017/CBO9780511753695>

Sekaran, U. (2000). Research methods for business. New York, NY: John Wiley \& Sons.

Sirkin, H. L., Keenan, P., \& Jackson, A. (2005). Hard side of change management. Harvard Business Review, 83(10), 108-118.

Smith, M. E. (2002). Success rates for different types of organizational change. In Performance Improvement (pp. 26-33): International Society for Performance Improvement. 